\title{
Study on Decision-making Method of the Site Selection of Industry Park
}

\author{
X.Y. XIONG \\ Hohai University, Nanjing, P.R. China,
}

\begin{abstract}
Based on the analysis of the site selection impact factors of industry park, the decision-making index system of site selection of industry park was built from the aspects of financial situation, the impact of site on society and nature, basic situation of park site, future development potential of park site, and the decision model of it is also built based on TOPSIS-GAHP model.
\end{abstract}

KEYWORD: Site selection of industry park; Decision-making of site selection; TOPSIS; GAHP

\section{INTRUCTION}

The scientificity of the site selection of industrial park has a direct impact on its investment, economic benefit, and even the decision of investors. As an important part of China's economic development, its development has been a focus for local governments at all levels. A industrial park, with good location, rich resources and complete supporting facilities, can make full use of its business, and also promote economic efficiency and society efficiency for local area. [1]

As the key part of the development of industrial park, its site selection will directly impact the construction speed and investment passion of its investors, and also will have a great impact on the environment and society state for the local area, as well as on society security, economy and life, environmental protection, transportation, agricultural production, etc.[2]. Therefore, it is significant to select a scientific and reasonable site for industrial park.

\section{ANALYSIS OF THE INFLUENCING FACTORS OF THE SITE SELECTION OF INDUSTRIAL PARK}

The influencing factors of site selection of industrial park mainly include infrastructure construction, markets around, environment, resources, etc.

(1) Infrastructure construction

For industrial park, the complete infrastructure facilities, such as internal road traffic, fuel lines, electronic power, post and telecommunication, etc. are important factors which have a direct impact on the future potential development and investor attracting of the industrial park [3].

(2)Markets around

The industries of industrial park always refer to manufacturing and service; therefore, its site selection should be close to the target customers according to the production and service provided by the park. The combination of production area and marketing area can reduce the transportation cost of local industry in the park, thus to reduce the total cost of the businesses in the park.

\section{(3)Environment}

The site selection should take a full consideration of environmental factors, including natural environment and social environment. On one hand, natural environment should be considered. Some industries, especially the ones with high pollution, should be built in the downwind of the park to avoid polluting the urban environment; on the other hand, society environment should be considered, such as local government policy, tax system, and local customs and culture, etc.

\section{(4)Resources}

The basic situation, such as raw material, fuel, water source, human resources, should also be taken a full consideration for site selection according to the orientation of the park and the layout of the future business in the park [4]. For example, if there are many water-needed enterprises, the site should be close to the river. 


\section{THE DECISION-MAKING INDEX SYSTEM AND MODEL BUILDING OF INDUSTRY PARK SITE SELECTION}

\subsection{The decision-making index system building of park site selection}

The first problem is index system building, which is premise and basis of selecting a site for a industrial park. When building a specific decision-making index system of industry park, it must be reasonably conducted according to the influencing factors of the site and on the basic principles of scientificity, systematicness, representativeness and independence.

According to the above analysis, the influencing factors of park selection mainly include market, environment, resources, infrastructure facilities, etc. While, through the reorganization of influencing factors, we can see that all these influencing factors can be concluded as finance, impact on society and nature, basic situation of park site, future development of park site, which is consistent with balanced score card (BSC).

According to balanced score card, the optimal index system of park site selection is built from the perspectives of finance, impact of park site selection on society and nature, basic situation of site, future development potential of park site. The optimization index system of park site selection built in this paper is shown in Table 1.

Table 1 Decision-making index system of park site selection

\begin{tabular}{|c|c|c|}
\hline Target level & First grade index & Secondary grade index \\
\hline \multirow{15}{*}{$\begin{array}{l}\text { Decision-making } \\
\text { of park site } \\
\text { selection }(\mathrm{O})\end{array}$} & \multirow{3}{*}{ Financial situation $\mathrm{X}_{1}$} & Park building expenses $U_{11}$ \\
\hline & & Surrounding business environment $\mathrm{U}_{12}$ \\
\hline & & Business circle radiation scope $U_{13}$ \\
\hline & \multirow{7}{*}{$\begin{array}{l}\text { Impact of park site selection } \\
\text { on society and nature } \mathrm{X}_{2}\end{array}$} & The impact of park site selection on surrounding land use $\mathrm{U}_{21}$ \\
\hline & & The impact of park site selection on surrounding sights resources $U_{22}$ \\
\hline & & The impact of park site selection on life quality of near residents $U_{23}$ \\
\hline & & The impact of park site selection on local history and culture $\mathrm{U}_{24}$ \\
\hline & & The impact of park site selection on surrounding land bio-environment $\mathrm{U}_{25}$ \\
\hline & & The impact of park site selection on air pollutant discharge $\mathrm{U}_{26}$ \\
\hline & & The impact of park site selection on surrounding river ecology $U_{27}$ \\
\hline & \multirow{3}{*}{ Basic situation of park site $X_{3}$} & The impact of park site selection on internal infrastructure $\mathrm{U}_{31}$ \\
\hline & & The impact of park site selection on surrounding transportation $\mathrm{U}_{32}$ \\
\hline & & Complexity of park land obtaining $\mathrm{U}_{33}$ \\
\hline & \multirow{2}{*}{$\begin{array}{l}\text { Future development potential } \\
\text { of park site } X_{4}\end{array}$} & Complexity for future extension $\mathrm{U}_{41}$ \\
\hline & & Development prospect of park $\mathrm{U}_{42}$ \\
\hline
\end{tabular}

\subsection{The establishment of decision-making model of industry park based on TOPSIS-GAHP}

According to the above designed program of optimal index system for industry park, it can be known that site selection program optimization is a complex system, involving lots of evaluation factor, in which there are uncertain and incompatible information of factors, and sometimes the evaluation factors between single indexes are incompatible. Meanwhile, in this system, most of the indexes are not numerical value, which requires experts to evaluate and get relevant value. Moreover, generally, the site selection of park need to select the optimum program among prepared programs, thus the decision-making model should have program optimization function. TOPSIS-GAHP can meet this requirement.

The processes of decision-making model building of park site selection based on TOPSIS-GAHP include the following steps [5][6][7]:

STEP1: Establish industry park site selection index system

The park site selection index system establishment is shown in Table 1.

STEP2: Decide the weight of each decisionmaking index of park site selection

This paper uses group analytic hierarchy process (GAHP) to determine decision-making index system weight of industrial park. By using GAHP method, first to invite experts to determine decision-making index system weights in accordance with AHP, and conclude the views of each expert, and take the arithmetic mean of experts' index weights evaluation results as the final weight for each index.

STEP3: Establish a single factor evaluation matrix

The establishment of a single factor evaluation matrix requires three steps, namely: 
(1) Determine the characteristic matrix of a single index $X$

$m$ decision-making index groups of industrial park site selection consist of $n$ evaluation values of alternative sites. Index characteristic values can be used to present the evaluation of each industrial park site decision indicator on $\mathrm{n}$ alternate sites, namely

$$
X=\left(\begin{array}{ccc}
x_{11} & \ldots & x_{1 n} \\
\vdots & \ddots & \vdots \\
x_{m 1} & \cdots & x_{m n}
\end{array}\right)=\left(x_{i j}\right)_{m \times n}
$$

In the above formula: $x_{i j}(\mathrm{i}=1,2, \ldots, 15 ; \mathrm{j}=1$, $2, \ldots, \mathrm{n})$ is the index characteristic value of the $i$ evaluation index for the $j$ alternative sites.

In the decision-making index system of industrial park site built in this study, none of the indicators can be directly characterized by numerical value, which is called qualitative indicator. For such indicators, its characteristic quantity is determined by following methods:

For qualitative indicators, its characteristic quantity is determined through expert evaluation. Because of the different qualitative indicators have different evaluation contents, therefore, this study will make an agreement for different types of qualitative indicators, indicators reviews set and indicator values.

In this study, the evaluation results of the 15 indicators of the index system can be classified as five grades of "very $\operatorname{good} "\left(\tilde{V}_{1}\right), \operatorname{good} "\left(\tilde{V}_{2}\right)$, "average" $\left(\tilde{V}_{3}\right)$, "poor" $\left(\tilde{V}_{4}\right)$, "very poor" $\left(\tilde{V}_{5}\right)$, namely $V=\left\{\tilde{V}_{1}, \tilde{V}_{2}, \ldots, \tilde{V}_{i}, \ldots, \tilde{V}_{5}\right\}$, define it respectively corresponding to $1.0,0.8,0.6,0.4$ and 0.2 . The appropriate evaluation activities for these four indicators are conducted mainly through investigation, which means to invite each expert to carry out investigations independently, and process and analyze data, and take arithmetic mean value corresponding to the values of each expert's evaluation result as index evaluation value under the site selection decision-making index of industry park.

(2) Determine index membership degree matrix $R$

After the determining characteristic quantity of each evaluation index, the following calculation should calculate each index corresponding to priority. In the index system establishment of this study, all the indexes are the larger the more superior.

As for a larger and superior indicator, its membership degree can be calculated by using the following formula.

$$
r_{i j}=\frac{x_{i j}}{x_{i \max }+x_{i \min }}(j=1,2, \ldots, \mathrm{n})
$$

In the formula: $r_{i j}$ shows degree of the index $i$ of the alternative site $j$;

$$
x_{i \max }=\max _{j}\left\{x_{i j}\right\}, x_{i \min }=\min _{j} n\left\{x_{i j}\right\} .
$$

According to formula (1) and (2), index characteristic matrices can be converted to an index membership degree matrix:

$$
R=\left(\begin{array}{ccc}
r_{11} & \cdots & r_{1 n} \\
\vdots & \ddots & \vdots \\
r_{m 1} & \cdots & r_{m n}
\end{array}\right)=\left(r_{i j}\right)_{m \times n}
$$

$\mathrm{i}=1,2, \ldots, 15 ; \mathrm{j}=1,2, \ldots, \mathrm{n}$.

(3) Determine the ideal alternative sites and negative ideal alternative sites

The subordinate degree of ideal alternative site should be the maximum value of relevant index subordinate degree among all alternative sites.

Namely

$$
\mathrm{R}^{*}=\left(\mathrm{r} 1^{*} \quad \mathrm{r} 2 * \ldots \mathrm{r} 3 *\right)
$$

In which, $\mathrm{ri}^{*}=\max _{j}\left\{x_{i j}\right\}(i=1,2, \ldots, 15)$.

The subordinate degree of negative ideal alternative site should be the minimum value of relevant index subordinate degree among all alternative sites.

Namely

$$
\mathrm{R}-=(\mathrm{r} 1-\mathrm{r} 2-\ldots \mathrm{rm}-)
$$

In which, $r_{1}^{-} \min _{j}\left\{x_{i j}\right\} \quad(i=1,2, \ldots, 15)$.

STEP4: Final evaluation

(1) Find the difference among each alternative sites, ideal alternative sites and negative ideal alternative sites

Using Euclidean distance to measure the difference, the difference degree of alternative site $j$ between the ideal alternative site and negative ideal alternative site respectively is $d_{j}^{*}$ and $d_{j}^{-}$.

$$
\begin{gathered}
d_{j}^{*}=\sqrt{\sum_{i=1}^{m} W_{i}\left(r_{i j}-r_{i}^{*}\right)^{2}} \quad, j=1,2, \ldots, \mathrm{n} \\
d_{j}^{-}=\sqrt{\sum_{i=1}^{m} W_{i}\left(r_{i j}-r_{i}^{-}\right)^{2}} \quad, j=1,2, \ldots, \mathrm{n}
\end{gathered}
$$

(2) Calculate the closeness of each alternative site and the ideal alternative site

Define the closeness of alternative site and ideal alternative sites $j$ as $C_{j}$, shown as follows:

$$
C_{j}=d_{j}^{-} /\left(d_{j}^{*}+d_{j}^{-}\right)
$$


Generally, $0 \leq C_{j} \leq 1$, the closer the value of $C_{j}$ to 1 , the higher level of the relevant alternative sites belongs to optimal. Order each alternative site according to the size of $C_{j}$, and then select the best industrial park site.

\section{CONCLUSION}

Site selection of industrial park is a systematic work, which involves many aspects like society, economy, culture and politics, etc. and needs coordinated consideration. On this basis, this paper analyzes the influencing factors in site selection of industrial park, builds a decision-making index system of industrial park, and builds a decision-making model of park site selections based on TOPSIS-GAHP, which provide a support for the scientific work of the site selection of industry park.

\section{ACKNOWLEDGEMENT}

This work is supported by: The national social science fund (13BJY158) - Special financial education funds input mechanism research.

\section{REFERENCES}

[1] Boushehr, Iran Hasanzadeh, Mansoureh Danehkar, Afshin, Environmental site selection for oil jetty using the analytical network process method case study. Ocean Engineering, v 77, p 55-60, 2014.

[2] Yal, Gözde Pinar; Akgün, Haluk. Landfill site selection utilizing TOPSIS methodology and clay liner geotechnical characterization: A case study for Ankara, Turkey. Bulletin of Engineering Geology and the Environment, v 73, n 2, p 369-388, 2014.

[3] Nazari, Abdolhadi; Salarirad, Mohammad Mehdi; Bazzazi, Abbas Aghajani. Landfill site selection by decision-making tools based on fuzzy multi-attribute decision-making method. Environmental Earth Sciences, v 65, n 6, p 16311642, 2012.

[4] Tu, Chang-Shu; Chen, Kee-Kuo; Chang, Ching-Ter; Lu, Hua-An. Applying an AHP - QFD conceptual model and zero-one goal programming to requirement-based site selection for an airport cargo logistics center. International Journal of Information and Management Sciences, v 21, n 4, p 407-430, 2010

[5] Mazumdar, Harajyoti; Das, Rictika; Hazarika, Dibya Jyoti; Choudhury, Indrani; Ahmed, Hasanul Islam, Factors associated with the cervical cancer patients: A comparative study on the rural and urban areas of Kamrup district, Assam. Journal of and Pharmaceutical Research, 2012, 4(2), 1370-1374.

[6] Liu Yuanxin; Zhuang Yan; Zhao Xing, Small hydropower's construction and relative financial analysis. Journal of and Pharmaceutical Research, 2013, 5(9), 263-267.

[7] Han Yuping; Ran Benqing; Xie Jiancang; Huang Mingcong, Application of Matter Element Model in Comprehensive Evaluation of Regional Water resources. Journal of China Agricultural University, 2003 (1), 31-36. 